\title{
Compañeros de viaje: La meta(no)ficción como artificio de verosimilitud en historias sobre migración*
}

\section{Liliana Chávez Díaz}

\section{Resumen}

Este artículo aborda el uso de la metaficción en historias de no ficción contemporáneas que exploran el tema del viaje y la migración desde una perspectiva latinoamericana. El estudio reflexiona especialmente en torno a la autorrepresentación del cronista y el espacio como una manera de identificar nuevas formas de encuentro con el otro en contextos de alta inestabilidad y violencia. Lo anterior se ejemplifica con el análisis de dos obras en formatos distintos: el libro Una luna. Diario de hiperviaje (2009), de Martín Caparrós y el texto de Óscar Martínez en el proyecto digital De migrantes a refugiados: el nuevo drama centroamericano (2017). A partir de un enfoque interdisciplinario que retoma teorías sobre intertextualidad y transmedialidad, se plantea una nueva lectura de la crónica latinoamericana del siglo XXI como un producto cultural colectivo y polifónico.

Palabras clave: metaficción, crónicas sobre migración, literatura latinoamericana de viaje, Martín Caparrós, Óscar Martínez.

\section{Travel companions: Meta(non)fiction as a literary device for credibility}

\begin{abstract}
This paper focuses on the use of metafiction in contemporary nonfiction stories exploring the idea of travel and immigration from a Latin American perspective. It particularly reflects on the cronista or storyteller's self-representation and space, as an attempt to identify new encounters with the other in highly unstable and violent contexts. This is shown through the analysis of two works published in diverse formats: Martín Caparrós's Una luna. Diario de hiperviaje (2009) and Óscar Martínez's text from the digital project De migrantes a refugiados: el nuevo drama centroamericano (2018). The paper considers an interdisciplinary approach, dealing with intertextuality and transmedia theories, and proposing a new reading of Latin American crónica for the 21st century which looks at the genre as a collective and polyphonic cultural product.
\end{abstract}

Este trabajo forma parte de las investigaciones que atendieron a la convocatoria sobre "Crónica Actual” realizada por la revista Literatura y Lingüística, en colaboración con el grupo de investigación de "Prensa y Literatura" de la Universidad Academia de Humanismo Cristiano.

" $\quad$ Mexicana. Doctora en Literatura Hispánica por la Universidad de Cambridge, en Reino Unido. Actualmente es investigadora postdoctoral en la Universidad Autónoma Metropolitana, Ciudad de México, México.lilianachavez@azc.uam.mx 
Keywords: Metafiction, Immigration chronicles, Latin American travel literature, Martín Caparrós, Óscar Martínez

"Cuando el reportero cuenta cómo se hizo pasar por otro y vivió una realidad que no es la suya, lo más interesante no es el recuento de ese mundo, sino los problemas que pasó para narrarlo."

Juan Villoro, El vértigo horizontal

Este artículo reflexiona en torno a los usos estilísticos e implicaciones éticas de la metaficción o, mejor dicho, la meta-no ficción, en crónicas o relatos de viaje y/o migración, publicados por autores latinoamericanos en el siglo XXI, en formato de libro y en plataformas digitales. Propongo un estudio de la crónica y discursos afines desde una perspectiva dialógica, que considere a estos textos en conversación con otros discursos sociales y artísticos (Bahktin 2011; Kristeva, “Word..., 1980). Al abordar el tema desde una metodología interdisciplinaria, tomando en cuenta conceptos de la teoría literaria, los estudios mediáticos y la praxis periodística, se espera que el tema ilumine algunas tendencias no solo del periodismo actual en América Latina, sino de las narrativas de no ficción en general. Propongo analizar tres de estas tendencias en torno al formato, género y estilo de textos híbridos, las cuales se manifiestan con mayor fuerza en autores provenientes de la tradición cronística o del periodismo literario.

En primer lugar, se identifica un desplazamiento de la crónica o el periodismo narrativo de su tradicional espacio en los diarios impresos - marginal o privilegiado, según el caso- a espacios alternativos. Por una parte, el género se está consolidando como producto literario al ser divulgado a través del formato de libro, como lo demuestran las recientes antologías de crónicas (Carrión, 2012; Jaramillo, 2012) y las obras de un solo autor, como aquellas de Leila Guerriero, Alma Guillermoprieto, Juan Villoro o Martín Caparrós, por mencionar algunos de los más sobresalientes. Por otra parte, los nuevos medios basados en las tecnologías computacionales han extendido las posibilidades creativas para el relato de no ficción, puesto que este ya no se basa solo en el texto, sino que utiliza sonido e imagen para ofrecer una crónica multimedia interactiva. Por lo tanto, el cambio de formato ha influido eventualmente en la forma y contenido de estas historias: tanto en formato de libro como 
en digital, las crónicas pueden ser ahora más extensas y contener mayor información que da credibilidad al relato, como fotografías, documentos en anexos o hipervínculos.

La segunda tendencia identificada es la creciente porosidad o inestabilidad del género de la crónica, pero también de las disciplinas que lo han sostenido. Ante textos tan diversos en temas y formatos es difícil -y ocioso quizá-, seguir discutiendo sobre sus límites y buscando definiciones que abarquen todos los tipos de discursos de intención no ficcional que intersectan los campos de la literatura testimonial, lo documental, la novela de no ficción, el periodismo narrativo o literario y las narrativas transmedia. En este sentido, la oscilación entre el empleo de "crónica", "relato" o "historia", así como entre "viaje" y "migración" en este artículo es deliberada: todas ellas son categorías de tradiciones discursivas distintas y, aunque no es la intención aquí crear más definiciones, sí se espera contribuir a una visión más amplia de la narrativa de no ficción que invite al debate en torno a las implicaciones y alcances del periodismo, la literatura y ese género híbrido de ambas: la crónica. Por otra parte, también se espera provocar discusión respecto del papel del cronista latinoamericano en el campo de la literatura de viajes, una tradición con mayor auge en la historia literaria europea que en la nuestra ${ }^{1}$. Si bien el cronista tiene que desplazarse usualmente para obtener la información que desea, esto no ha implicado necesariamente una consciencia del viaje como parte central del relato. Además, a la luz de los nuevos fenómenos de migración en el continente, creo que es válido replantearse si América Latina no estará forjando su propia tradición de relatos de viaje: una narración que se separa del diario de viaje convencional para documentar un viaje otro, ajeno al del conquistador del siglo XVI, el explorador científico del XIX o el turista burgués del XX. En este sentido, el tipo de obras analizadas aquí configuran un narrador que representa a un individuo que ya no viaja por placer o necesidad, sino por un trabajo específico, en este caso el del periodismo. En estas

Si bien hasta antes del siglo XIX, quienes viajaban por América Latina y escribían sobre ello solían ser europeos, hacia finales del siglo XIX los escritores modernistas de la región empiezan a desplazarse y escribir acerca de sus experiencias. En esta tradición de cronistas modernistas destacan los textos del cubano José Martí, sobre todo durante su trabajo como corresponsal en Nueva York para varios periódicos hispanos. Estos textos han sido recientemente analizados como antecedentes de la crónica contemporánea en América Latina (Rotker 2005), aunque su estilo linda más con el género del ensayo y la tradición hispanoamericana del artículo o columna en prensa escrita por intelectuales. 
obras se representa el viaje como método de obtención de información y la escritura del viaje como generadora de conocimiento. Su narrador es el tipo de viajero que Jorge Carrión (2009) ha identificado como el metaviajero posmoderno:

Un metaviajero de la posmodernidad última no solo observa con ironía la tradición histórica que lo precede, sino que además explicita en sus relatos de viajes junto a quién o qué está viajando, mediante técnicas autoconscientes como los fragmentos del diario que utiliza Sontag, las reflexiones ensayísticas que intercala el escritor argentino Martín Caparrós en su libro de crónicas Larga distancia, o los complejos mecanismos gráficos que despliega el autor de cómic Joe Sacco en sus obras sobre Palestina o los Balcanes. (26)

Finalmente, la tendencia que a mi parecer incluye las dos anteriores y hace evidente las diferencias entre la no ficción contemporánea respecto de otros periodos de su historia en la región es el empleo de la metaficción: esa muestra de autoconsciencia de la crónica sobre sí misma a través de la autorrepresentación de un cronista que comenta, opina e interpreta sin reparos en la vieja objetividad periodística. El uso de la primera persona para contar historias de otros ha suscitado debates públicos y privados entre los cronistas, durante los encuentros y talleres de la Fundación para un Nuevo Periodismo Iberoamericano, por ejemplo. Sin embargo, esta tendencia ha llamado poco la atención en los estudios literarios, quizá porque se asume como un recurso literario incluso anacrónico, puesto que ya fue explotado en los ochenta y noventa por la novela posmoderna, por mencionar solo sus usos más recientes en la historia literaria occidental (Hutcheon, 1984 y 1988) ${ }^{2}$. Considero que en la narrativa de no ficción latinoamericana de fin de siglo XX y principios de siglo XX la metaficción se ha convertido en un arma de doble filo. Por un lado, su mero empleo vincula al texto con el campo de las narrativas del yo (de la autobiografía, a las memorias y la autoficción). Si bien esta característica le otorga "literaturiedad", también le transmite

\footnotetext{
En este contexto, que es también el del posboom latinoamericano, surge el término "autoficción" para designar un tipo de ficción autobiográfica relatada por un narrador que se identifica nominalmente con el autor. Ejemplos de ello en la región son las novelas de Fernando Vallejo y Roberto Bolaño. Para una revisión crítica y panorámica sobre la teoría autoficcional y el desarrollo histórico del género en Hispanoamérica ver Diaconu (2017).
} 
rasgos de la ficción poco deseables para un texto con intención documental ${ }^{3}$. Por otro lado, considerando el contexto de alto riesgo y censura para los periodistas en nuestra región, se podría argumentar que la metaficción es empleada de modo distinto por el periodismo literario latinoamericano reciente y podría hablarse entonces de metaperiodismo o metacrónica. Narrar el proceso de la investigación periodística y autorrepresentarse es para el periodista latinoamericano una forma de protegerse y proteger a sus informantes, además de dar credibilidad a una historia que muchas veces no tiene más evidencias que la palabra del autor.

Este artículo propone, por lo tanto, analizar con mayor atención los alcances éticos de la elección de una forma, un género o un formato, en tiempos en que la credibilidad de los medios está a la baja y el riesgo de contar una historia sin ficción sigue siendo alto. El análisis inicia con una discusión crítica acerca de algunos conceptos en torno a la inserción de la voz del yo (narrador-periodista) y el otro (informante) en las narraciones. Esto permitirá delimitar el marco teórico desde el cual propongo, posteriormente, la lectura de dos obras que exploran el tema de la migración latinoamericana y global en formatos distintos: el libro Una luna. Diario de hiperviaje (2009), de Martín Caparrós, y "Los que iban a morir se acumulan en México", texto de Óscar Martínez dentro del proyecto transmedia De migrantes a refugiados: el nuevo drama centroamericano (2018).

\section{De la intertextualidad a la transmedialidad}

Julia Kristeva ("Word..." 1980) acuñó en 1966 el concepto de intertextualidad para referirse a la interrelación entre textos. La investigadora profetizó que el "principio dialógico" tendría importancia en un espacio de pensamiento más amplio que el de la novela:

dialogism may well become the basis of our time's intellectual structure. The predominance of the novel and other ambivalent literary structures; the communal, carnivalesque phenomena attracting young people; quantum exchanges; and current interest in the correlational symbolism of Chinese philosophy 
— to cite only a few striking elements of modern thought— all confirm this hypothesis. (89)

Con excepción, quizá de la filosofía china, el pensamiento moderno al que se refiere Kristeva en la cita anterior no difiere mayormente de las actuales búsquedas expresadas a través del internet y las redes sociales interactivas. Los prefijos trans- e inter- también son empleados por Kristeva casi tanto como por los estudios contemporáneos respecto de intermedialidad, a los que se hace alusión más adelante. Para Kristeva, el texto es una de las muchas prácticas semióticas posibles y debe estudiarse mediante un método translingüístico, es decir, uno que considere su relación con otros sistemas de significado. En este sentido, el texto es una intertextualidad o una permutación de textos.

Si bien estas ideas han resultado iluminadoras para los estudios que relacionan narración y medios, es importante reconocer que desde otras disciplinas, como las ciencias computacionales, la idea de conectar textos entre sí mediante una estructura tecnológica también había empezado a estudiarse desde la década de los cuarenta. La manipulación electrónica de datos a través de un artefacto capaz de imitar procesos mentales había sido imaginada ya en Estados Unidos por el científico Vannevar Bush en un artículo de $1945^{4}$. Bush reconocía que el proceso lógico utilizado para ordenar la información en una biblioteca o archivo no era congruente con la forma en que los seres humanos piensan o crean, es decir, mediante asociación de ideas. Sobre la base de los avances científicos generados durante la guerra mundial, Bush inspiró los sistemas operativos que actualmente disfruta un usuario común de computadoras:

Consider a future device for individual use, which is a sort of mechanized private file and library. It needs a name, and, to coin one at random, "memex" will do. A memex is a device in which an individual stores all his books, records, and communications, and which is mechanized so that it may be consulted with exceeding speed and flexibility. It is an enlarged intimate supplement to his memory (parte 6, párr. 4).

Inspirado en la "Memex" de Bush, el filósofo y sociólogo estadounidense Ted Nelson propuso en 1965 un sistema de archivo electrónico que fuera capaz de resolver el problema de la organización de

La "Memex" podría considerarse la base de la actual Wikipedia. 
grandes cantidades de información, pero manteniendo un orden abierto, no lineal, sin jerarquías y con una estructura fácilmente modificable por el usuario según sus necesidades. Su propuesta partió del estudio del proceso cognitivo de la escritura. Su hipótesis era que dicho proceso, al menos en los casos de textos complejos, como los literarios, no tiene una secuencia lógica, sino que es un proceso de constante reordenación y reprocesamiento de fragmentos textuales que pasan por muchas revisiones antes de configurarse como una sola obra: "Intellectually they [the fragmentary texts] are juxtaposed, compared, adapted, transposed, and judged; mechanically they are copied, overwritten with revision markings, rearranged and copied again." (Bush 87).

Esta idea no está tan alejada del concepto de texto que iba a formular al año siguiente Kristeva ("The bounded text" 1980) para su teoría del texto delimitado o atado:

the text is defined as a trans-linguistic apparatus that redistributes the order of language by relating communicative speech, which aims to inform directly, to different kinds of anterior or synchronic utterances. The text is therefore a productivity, and this means: first, that its relationship to the language in which it is situated is redistributive (destructive-constructive), and hence can be better approached through logical categories rather than linguistic ones; and second, that it is a permutation of texts, an intertextuality: in the space of a given text, several utterances, taken from other texts, intersect and neutralize one another. (36)

Podría no ser casual, aunque no se han encontrado referencias para afirmarlo, que tanto Kristeva como Nelson justificaran sus reflexiones en torno a las formas de organización del conocimiento (textual) complejo asumiendo la necesidad de pensar más allá de la lógica lineal ${ }^{5}$. Siguiendo a Bakhtin, Kristeva considera la palabra literaria como una intersección de superficies textuales, más que un punto de significado fijo, es decir, "a dialogue among several writings: that of the writer, the addressee (or the character), and the contemporary or earlier cultural context" (65). De manera más práctica, aunque desde la misma perspectiva, Nelson

\footnotetext{
5 Por una parte, hay que considerar que Kristeva tuvo una formación en matemáticas antes de iniciar su carrera como teórica literaria. Por otro lado, el sistema que imaginó Nelson pretendía ser "the dream file" para resolver los problemas de organización de notas de los novelistas y profesores distraídos (85).
} 
buscaba un método que relacionara unidades discursivas entre sí, para lo cual acuñó el término hipertexto ${ }^{6}$ :

Let me introduce the word "hypertext" to mean a body of written or pictorial material interconnected in such a complex way that it could be presented or represented on paper. It may contain summaries, or maps of its contents and their interrelations; it may contain annotations, additions and footnotes from scholars who have examined it. [...] Such a system could grow indefinitely, gradually including more and more of the world's written knowledge. However, its internal file structure would have to be built to accept growth, change and complex informational arrangements. (96)

Años más tarde, quizá inspirado en el contexto tecnológico de su época, el compositor estadounidense Stuart Saunders Smith acuñó en 1975 el término trans-media music para nombrar a la variedad de melodías que se pueden distinguir en una obra determinada (Renó 2013). Este es el origen directo del término transmedia intertextuality aplicado por primera vez a los estudios mediáticos en 1991 por la investigadora Marsha Kinder, quien lo utilizó para denominar al fenómeno de contar distintas tramas de una misma historia por distintos medios; uno de sus ejemplos fue el caso de las “Tortugas Ninja” y sus diversas manifestaciones narrativas a través de dibujos animados, teatro o cine (Gosciola 2012). Dicho concepto originó el de transmedia storytelling y, recientemente, el más integrador de intermediality.

La narrativa transmedia puede definirse como la convergencia de medios para promover determinadas narrativas o contenidos a través de múltiples plataformas (Jenkins 2007). Por su parte, la intermedialidad es un concepto que incluye la narrativa transmedia, pero no se limita a ella. Marina Grishkova y Marie-Laurie Ryan (2010) aplican el término para referirse, de manera muy amplia, a todas las relaciones entre narrativa y medios: "In its broad sense, the one we endorse here, it is the medial equivalent of intertextuality and it covers any kind of relation between different media. In a narrow sense,

Como se verá más adelante, este concepto no es sinónimo del de Gérard Genette (1991). Nelson emplea el prefijo hiper- en el sentido de expansión, para referirse a unidades de significado más allá del texto. 
it refers to the participation of more than one medium - or sensory channel- in a given work" (3)

Parte de la confusión que puede suscitar esta evidente diversidad de nomenclaturas para fenómenos similares, deriva de que: algunas de estas categorías suelen entremezclarse en la práctica; es decir, una narrativa intermedial podría ser transmedial y multimodal a la vez; y algunos autores optan por emplear "transmedialidad" y otros por "intermedialidad" para referirse a un mismo fenómeno, el cual consideran sinónimo del de "intertextualidad" de Kristeva. La sustitución de "texto" por "medio", no obstante, merece mayor atención. Mientras que Kristeva ubica al texto en el centro de toda práctica semiótica (para ella, como para Bakhtin, la palabra es la unidad mínima de significado), me parece que hacer énfasis en el medio enfoca la atención hacia la plataforma de producción y difusión de la obra, que en el caso de los nuevos medios incluye, por supuesto, uno o múltiples textos (en el sentido lingüístico convencional del término), pero también imágenes y sonidos. ¿Cómo, entonces, acercarse a una producción textual cuya forma y contenido depende de una plataforma digital y ya no más de una hoja de papel?

La teoría dialógica-intertextual coincide con la lógica no-lineal e interactiva propia de las interfaces digitales, por lo que no sorprende que siga siendo referencia obligada en los estudios transmediáticos o intermediales. Sin embargo, esta teoría puede ser insuficiente al momento de realizar un análisis más detallado de las diversas estructuras de sentido que se intersectan en una obra artístico-mediática contemporánea.

Unos años después que Kristeva, y en el mismo contexto de desarrollo tecnológico que propició los primeros estudios transmediáticos, Gérard Genette (1991) propuso un método architextual para estudiar los tipos o funciones de las diversas relaciones entre textos, el cual fue desarrollado a mayor profundidad bajo el nombre de transtextualidad. Su propuesta incluye cuatro formas de relación entre textos, dos de las cuales ya habían sido empleadas, como se sabe, por otros autores: la intertextualidad, desde los estudios literarios, y la de hipertextualidad, desde las ciencias computacionales.

Las académicas identifican tres categorías de intermedialidad: transmedialidad, para referirse a fenómenos cuya manifestación no está sujeta a un medio en particular, como el lenguaje en sí mismo; plurimedialidad o multimodalidad, para objetos artísticos que emplean cualquier sistema semiótico; transposición intermedial, para adaptaciones de un medio a otro; y referencia intermedial, para textos que tematizan otro medio, los citan, describen o los imitan formalmente. 
Sin duda las tecnologías hipertextuales afectan a los distintos formatos a través de los cuales se transmite la historia. No obstante, considero que el modelo conceptual de Genette ofrece mayores posibilidades de trabajo cuando se trata de analizar las narrativas de no ficción desde una perspectiva literaria y no meramente técnica. Por otra parte, al contrario del modelo de Bakhtin y Kristeva — cuyo análisis parte primordialmente de las relaciones entre palabras al interior de cada texto según su género (por ejemplo, la novela)—, la teoría de Genette actúa a nivel de las relaciones más generales, pero profundas, entre una obra y otra. Este enfoque, por lo tanto, permite identificar "lo literario" en una obra altamente polifónica y cuyo sentido depende cada vez más de las acciones y preferencias del lector.

Si bien Genette aplica su teoría sobre todo al estudio de novelas, su propuesta no depende de las relaciones entre géneros discursivos para identificar la "literaturiedad" o la trascendencia de una obra determinada, sino de las funciones que dicha obra transtextual tenga, desde el punto de vista del receptor. Por lo tanto, sus categorías pueden ser de mayor utilidad para estudios que consideren obras pertenecientes a géneros o disciplinas híbridas, como es el caso de la crónica.

A continuación, se analizan dos casos de textos que presentan relaciones con otros discursos, donde la voz autoral predomina como mediadora entre las voces de quienes dan su testimonio. De esta manera se busca explorar las diversas representaciones contemporáneas de los testimonios y sus propias relaciones trans/intermediales. Para Genette, la metatextualidad, también llamada "comentario", es la relación crítica de un texto con otro, sobre el que se habla sin necesidad de citarlo. Tanto la obra de Martín Caparrós como la de Óscar Martínez se sitúan en este nivel de relaciones transtextuales, puesto que retoman un texto (digamos, la voz del otro relatando su historia en entrevista) y dialogan con él dentro de su propio texto (la crónica per se). En el caso del texto impreso el texto del otro está diferenciado de aquel del autor por medio de comillas o guiones, pero en la red las opciones son mayores: se pueden insertar videos o audios que pretenden dar la opción al usuario-lector de acceder de manera directa a la voz del entrevistado. 


\section{Una luna. Diario de hiperviaje: Conversaciones locales en tiempos globales}

El novelista, historiador y periodista argentino Martín Caparrós (nacido en Buenos Aires, 1957) es considerado uno de los mejores cronistas en América Latina actualmente; su obra en y sobre este género es bastante amplia y su nombre aparece con frecuencia en las antologías y estudios de crónica de las últimas décadas. Su narrativa surge en el contexto literario del posboom latinoamericano y de la cultura posmoderna global; en particular, sus obras de no ficción destacan por la configuración de una fuerte voz narrativa en primera persona, autorreferencial y autorreflexiva, que guía al lector hacia el encuentro con "el otro", generalmente un individuo marginal y representante de un problema social que el autor busca comprender. El carácter eminentemente metaficcional de su narrativa puede observarse desde su primera antología de crónicas de viaje, Larga distancia (1992), hasta su más reciente libro documental $E l$ hambre (2014) $)^{8}$.

Retomando ideas en torno al giro documental en las narrativas hispánicas, en línea con las teorías del enfoque documental de Julio Rodríguez-Luis (1997) y de la escritura facticia de Albert Chillón (2014), María Angulo Egea ("El realismo intransigente..." 2016) ha identificado en la obra documental de Caparrós un "impulso antropológico" derivado de la etnografía confesional, al que propone denominar "realismo intransigente", puesto que surge de un entrecruzamiento entre compromiso político, conciencia histórica y voluntad literaria (642643). Una aproximación global y política a la obra de Caparrós como la de Angulo Egea resulta útil para entender el papel de este autor en la historia reciente del periodismo literario en Argentina y de la narrativa hispanoamericana en general. No obstante, mi análisis propone una lectura transmediática que permita identificar los alcances de "lo literario" en las narrativas documentales y, por lo tanto, me centro en los recursos estilísticos formales de la escritura de Caparrós, especialmente en lo que propongo denominar meta(no)ficción.

\footnotetext{
$8 \quad$ En 2016 la editorial Planeta publicó La crónica, una compilación de sus crónicas, seleccionada y comentada por el propio Caparrós; este volumen enfatiza aún más el estilo metaficcional del autor. Cada texto es precedido por una metacrónica: la historia de cómo Caparrós conoció a sus informantes, se interesó por el tema o alguna otra anécdota o reflexión posterior acerca de la crónica.
} 
En esta sección me enfocaré al análisis de Una luna..., una obra breve que no ha sido considerada por él mismo como crónica, puesto que no fue planeada como tal, sino como un regalo para sus amigos al celebrar su cumpleaños (Chávez Díaz 2017). En este libro, la hibridez discursiva va más allá de la definición tradicional y prescriptiva del género crónica, tal como Caparrós advierte a su lector: "Esta no es una crónica: es solo un diario de hiperviaje" (62). Al añadir el prefijo "hiper-", el viaje de Caparrós en este libro deja de ser un viaje cualquiera. El autor intenta un viaje en exceso, es decir, que excede los límites de la definición tanto de viaje como de diario y hasta los de una crónica convencional.

Una luna... surge de las notas de viaje que Caparrós tomó mientras participaba como relator para un proyecto del Fondo de Población de las Naciones Unidas sobre jóvenes migrantes en el mundo y que se publicó sin autoría como Jóvenes en movimiento (2007). Una luna... es un libro que no esperaba ser publicado o, al menos, eso expone el narrador cuando nos cuenta:

Hasta hoy — hasta ahora, sentado en este bar de Ámsterdam, con tanto frío afuera y adentro leve soledad- no había pensado que esto pudiera disfrazarse de libro. Yo solo tenía que armar mis historias sobre inmigrantes jóvenes. Pero desde que salí que estoy tomando notas - porque todavía no aprendí a viajar de otra manera. Lo intento, lo intento, pero no. Y ahora - un cigarrillo fuerte, una cerveza belga, tres amigos que gritan en la mesa de al lado-, cuando miro las notas que se han ido acumulando imagino que quizá tengan algún sentido -y pienso en publicarlas porque todavía no aprendí a escribir para el silencio. Lo intento - fuertemente lo intento- pero no todavía. (62)

El autor utiliza la metaficción como un artificio concreto para relacionar su texto con uno previo y con las voces de los migrantes que han originado ambos proyectos. De esta manera da solución al problema que el texto original (el reporte para la ONU) le ha provocado: "En principio tienen que estar en tercera persona y tener menos de dos mil palabras. En mis crónicas, dos mil palabras es lo que suelo usar para aclararme la garganta. Y, peor, el problema de contar sin incluirme: la tarea de desaparecer. Un buen ejercicio, me digo: un desafío - y otra manera de viajar." (15). 
El problema para el cronista contemporáneo, como lo hace notar Caparrós en esta confesión al lector, es desaparecer del texto. Si el reporte se limita a narrar en tercera persona y de manera sintética las historias de vida de los migrantes, el libro retoma el material y establece un diálogo con la experiencia de otro viajero que los sigue y que se convierte en narrador-personaje. Solo a través de su propia experiencia de viaje, documentada en breves notas, Caparrós-narrador es capaz de hacer sentido del fenómeno migratorio global, a la vez que escapa por medio de la escritura de una realidad difícil de sobrellevar. Estas notas privadas y sueltas escritas en el camino, sin propósito aparente, entablan una relación concreta con esas voces que también le hablaron directamente al informante de la ONU, aunque el género del reporte internacional nogubernamental no tuviera cabida para ellas.

Escrito originalmente como un proyecto personal independiente al reporte, al publicarse como libro Una luna... se convierte en la respuesta subversiva de un autor que no puede esconderse detrás de un texto en tercera persona. Los jóvenes migrantes le han contado su historia a una persona específica; Una luna... pretende mostrar que cada historia individual es también la historia del autor-editor de esas historias y la de sus viajes para escucharlos. Una luna... aspira a la historia colectiva, polifónica. No obstante, la fuerza de la autorrepresentación hace dudar de esta intención.

Caparrós-narrador se configura como un viajero de negocios. Al contrario de aquellos que viajan por placer o en busca de aventuras, o más aún, de aquellos que viajan por necesidad — como sus propios informantes para el reporte-, este narrador viaja para trabajar en un mundo globalizado que hace posible transportar el cuerpo de un lado al otro del mundo, el hiperviaje:

El desierto allá abajo es bellísimo y marrueco, plagado de colores. El chardonnay es chileno, el sauvignon neozelandés, francés el foie, el salmón canadiense; el señor de mi izquierda es norteamericano, el de mi derecha senegalés, pero los tres somos oenegeros leyendo reportes sobre miseria y emergencias sociales en el oeste de África. Es clase Hombres, por supuesto: la solidaridad bien entendida empieza por sí mismo. (35)

Al incluirse en la crónica respecto de la migración de seres marginados, Caparrós cuestiona no solo la naturaleza globalizada del viaje contemporáneo, sino también el papel de las instituciones 
humanitarias que pretenden salvar al mundo mientras sus representantes viajan en primera clase. Las condiciones de esta forma privilegiada de viaje le permiten al narrador una forma de escritura de diario cada vez más alejada del periodista o el antropólogo convencional. Registrar lo que observa y escucha ya no es una forma de preservar los hechos, sino una manera de tratar de entender lo que le está pasando.

Una luna... no solo dialoga con las notas que Caparrós escribió durante el viaje, aunque sea constante el libre discurrir de la consciencia como estrategia narrativa en el libro. El narrador también recurre a su memoria y a la investigación posterior. A diferencia del pacto de credibilidad con el lector que propone una crónica periodística, este texto pone en entredicho la fiabilidad del cronista para narrar la realidad. Un ejemplo de ello es una escena de observación participante en la cual el narrador se encuentra con unos hombres en un bar de Lusaka y cree que descubre una auténtica experiencia local: “Once de la mañana: en el Stanley Bar, los hombres toman leche. Hay una forma rara de mi felicidad en viaje: caminar, caminar, más o menos entretenido, más o menos no, y dar de pronto con un lugar que me ilumina la cara: ese lugar que sí valía la pena." (161).

En la página siguiente, el lector se encuentra con otra interpretación del hecho y asiste, junto con el cronista, a la desmitificación de la anécdota:

El viajero no sabe una mierda. Supone, busca, piensa, afirma y muchas veces sigue suponiendo. Los muchachos del Stanley Bar no tomaban leche: en esos tetras blancos tan lechosos, con letras que decían shake shake, de donde salía un líquido tan leche, había una chicha, una bebida alcohólica de maíz fermentado que aquí llaman chibuku. Me lo dicen ahora, camino al aeropuerto, y puedo corregirlo. Pero fue un azar: lo más lógico habría sido no enterarme nunca. ¿Hasta qué punto hay que seguir averiguando o, dicho de otro modo, desde qué punto desconfiar? ¿Si veo una bebida con nombre de leche que sale de un recipiente de leche y es igual a la leche, debo decir que es leche? ¿O debería, mejor, dejar claro lo que podría ser evidente: que un señor mirando es un señor mirando, no el garante de la verdad divina? (162)

El cronista de Una luna... se sorprende, se equivoca, corrige, miente y desmiente, aún a costa de perder la credibilidad de sus lectores. Estas 
estrategias narrativas, no obstante, sostienen una postura crítica ante la imposibilidad de mantener confianza en los métodos de investigación basados en la mera observación. Si bien Una luna... no resulta una pieza confiable de periodismo tradicional, sí puede reclamar un lugar como expresión honesta de la experiencia humana que es un encuentro entre desconocidos.

A diferencia de las historias en el reporte para la ONU, escritas en tercera persona, en Una luna... Caparrós utiliza el diálogo para representar su encuentro con los otros. A través de guiones, el lector asiste a una conversación fragmentada, editada, pero que pretende ser fiel a la entrevista grabada que originalmente se realizó como evidencia para el reporte. Si estilísticamente la desaparición del narrador-entrevistador en el reporte puede ser interpretado como una forma de dar la voz directa a los otros, esto también restringe la pluralidad de significados que el encuentro real puede tener entre el periodista y ellos. Una comparación detallada de ambas versiones de las historias, las del reporte y las del libro, ejemplifica las implicaciones éticas que una decisión estilística puede tener en un discurso documental. Un ejemplo es la historia de Natalia, una joven de Moldavia que fue vendida por su esposo a un traficante de mujeres. En el reporte, su historia inicia con el relato de una infancia de pobreza, pero en el libro Caparrós inicia contando su propio viaje para conocerla. Mientras que la historia del reporte aparece aislada del resto de historias, fuera del contexto que la hace posible o justificable más allá de ser una historia de migración más, en el libro el narrador no esconde sus percepciones del lugar y la persona que entrevista. Al representarse a sí mismo en el contexto de la entrevista, Caparrós permite que el lector asista a un tras bambalinas de la escena, un detrás de cámaras que permite descubrir aspectos más profundos de la situación que el reporte. La historia de vida se convierte, entonces, en un espacio dialógico que evoca una situación real, pero también la modifica mediante el lenguaje. Aunque la historia de Natalia es en esencia la misma, los comentarios personales del autor influyen sin duda en el sentido que la conversación tendrá para el lector. A continuación, se transcribe una de las conversaciones entre Caparrós-narrador y Natalia, resaltando en negritas las partes que solo están incluidas en la versión del libro:

— ¿Por qué hablás con nosotros y no con tu familia?

-Porque ellos nunca me entenderían. Yo primero quería ocultar mi historia, porque acá en mi país cuando se enteran 
te discriminan, no te tratan como víctima sino como culpable. Pero ahora sé que tengo que contarlo: si no, me voy a pasar toda la vida pensando en esos meses. Contarlo es la manera de dejarlo atrás y de ayudar a que no les pase a otras chicas como yo.

Dice Natalia, pero no quiere que su cara se vea clara en las fotos. Todos los expertos coinciden en que el tráfico es solo la punta del iceberg de la migración -y que seguirá mientras sigan la pobreza y la falta de perspectivas que la causan: mientras el noventa por ciento de los jóvenes moldavos siga pensando en emigrar, mientras haya mujeres que prefieren arriesgarse a lo desconocido antes que seguir en un lugar que no les ofrece ninguna posibilidad.

—¿Qué esperás del futuro?

Natalia se calla, piensa, intenta una sonrisa, se restriega con un dedo el ojo falso. Afuera nieva. Lo bueno de la nieve es que vaga en el aire: allí donde la lluvia cae, la nieve flota, hace como si no tuviera un fin, como si no quisiera nada.

—Qué pregunta difícil.

Dice, tras haber contestado tantas preguntas imposibles. (27-28)

Aunque el reporte incluye preguntas, estas no indican quién es el entrevistador. En el libro, por el contrario, el lector puede identificar incluso la nacionalidad de quien pregunta, quien utiliza la acentuación argentina en palabras como "hablás" o "esperás". Además, el libro permite un acercamiento más completo a la personalidad de Natalia, quien se convierte en personaje y ya no solo en informante de su propia historia. La historia de Natalia continúa incluso después de la entrevista, a través de un narrador que la observa y registra sus movimientos:

Natalia y yo estábamos sentados uno al lado del otro pero los dos mirábamos a Alexandrina, que traducía del moldavo al inglés, del inglés al moldavo. Acabo de pasarme cinco horas escuchando a una chica con un ojo de vidrio y una vida tan dura que su marido la entregó, embarazada de él, a un traficante y todo el resto. Hay cosas que no se pueden escuchar impunemente. (28) 
Caparrós deja ver las costuras de la historia al mostrarnos el procedimiento de traducción para que la historia de Natalia llegue a nosotros. Además, este pasaje muestra otra tendencia interesante de la crónica contemporánea: su acercamiento al género del ensayo ${ }^{9}$. Podría decirse que esta tendencia está de vuelta, ya que la relación entre ensayo y crónica se encontraba presente en el estilo y mirada de los escritores modernistas (Mahieux 2011; Rotker 2005). Pienso que esa tradición híbrida entre el ensayo y la crónica obedece al perfil inicial de los autores que consolidaron el género en la prensa latinoamericana. Estos escritores provenían del campo de la literatura, pero empezaban a hacer uso del periodismo como una manera de ganarse la vida y aumentar su prestigio social (González 2006), desde Rubén Darío, Amado Nervo, Manuel Gutiérrez Nájera y José Martí hasta Roberto Arlt, Salvador Novo y, ya más entrado el siglo XX, Gabriel García Márquez o Rodolfo Walsh, por mencionar solo algunos ejemplos. Hacia finales del siglo XX, no obstante, identifico que la crónica tomó dos caminos en campos culturales distintos, aunque paralelos y conectados: desde el campo literario, se continuó la tradición modernista con un estilo más opinativo-interpretativo respecto de las escenas de la vida política o cotidiana del entorno personal del escritor, con una fuerte presencia de un narrador en primera persona autorreferencial, mientras que desde el campo periodístico se optó por una crónica cuyo contenido se deriva de una investigación periodística exhaustiva de un tema "noticioso", empleando técnicas de las ciencias sociales y escrita en tercera o primera persona, pero con un foco primordial en la historia de los "otros" (informantes) ${ }^{10}$. Caparrós, en mi opinión, inicia su trabajo cronístico bajo esta última visión de la crónica periodística, pero eventualmente su formación académica como historiador y su interés por la experimentación con el lenguaje literario lo llevarían por un camino más híbrido, y más posmoderno quizá. De esta manera, en sus obras de no ficción más recientes - como Contra el cambio (2010) y El hambre (2014) — se percibe un interés mayor por la búsqueda de la

Para una discusión más amplia acerca de la historia y crítica del ensayo latinoamericano ver Skirius (2004) y Weinberg (2014).

10 Un caso emblemático en el México contemporáneo que siguió conservando la tradición de la crónica-ensayo es Carlos Monsiváis; John Kraniauskas (1997) ha analizado su estilo bajo la categoría de chronicle-essays o "croniensayos". 
interpretación de la experiencia narrada y de la crónica como método de generación de conocimiento ${ }^{11}$.

En Una luna..., el narrador Caparrós se permite opinar, mostrar su enojo ante la situación que enfrenta Natalia, una historia que más adelante en el libro motivará una crítica a la prostitución en Europa. Mientras que la edición de la palabra del otro, mediante entrecomillados o diálogos, es una estrategia para incluir la visión aparentemente sin filtro de sus protagonistas, la metaficción es la solución autoral para insertarse en esas historias ajenas, para controlar, hasta cierto punto, la interpretación de los hechos:

¿Qué hago entonces? ¿Empiezo por contarla, como mandan los cánones del buen viejo nuevo periodismo, y después sigo con mi reflexión? ¿La ignoro porque parece demasiado a propósito, casi inventada? ¿Trato de darle verosimilitud con algún dato o detalle que la singularice y complemente? $i \mathrm{O}$ me armo una pequeña discusión sobre qué hacer y así ya nadie duda de que la historia era real y mis intenciones las mejores? (159)

Esta estrategia es utilizada con frecuencia en narrativas de no ficción en las que el narrador-periodista se autorrepresenta escribiendo en tiempo real sobre lo que observa a su alrededor. Desde la mesa de un café parisino, por ejemplo, Caparrós-narrador trata de recordar una entrevista que había realizado un mes antes a un pandillero en El Salvador: "Trato de pensar cómo era todo hace unos días, cuando estaba sentado en el coche de un pandillero salvadoreño, estacionado en la puerta de su casa de un barrio duro, nueve, diez de la noche, y él me hablaba y pasaban las sombras a los lados" (88). En este y otros momentos del viaje se exhibe la dislocación del cronista: el lugar de la escritura casi nunca es el mismo que el lugar de los hechos. Ciudadano global, el narrador de Una luna... ha abandonado ya cualquier intento de controlar la historia; no puede convertir el testimonio de los otros, ni sus propios recuerdos, en una narrativa coherente y verosímil.

11 Este artículo no se propone el análisis de la obra de Caparrós in extenso, pero puede consultarse el estudio de Angulo Egea (2016) para mayor profundización sobre el tipo de periodismo literario propuesto por el autor. 


\section{De migrantes a refugiados: crónicas en movimiento}

En América Latina el testimonio del otro, generalmente la víctima o el testigo de alguna situación de conflicto, sigue siendo un discurso mediado por la voz del intelectual letrado ${ }^{12}$. Si en la obra de Caparrós las relaciones intertextuales con otros discursos ocurren solamente a través de la palabra escrita, en las historias de no ficción transmitidas a través de internet la palabra del otro dialoga también con los discursos del diseño, la animación, la fotografía y el video. Esta modificación no es menor, ya que altera la estructura narrativa del testimonio y, por ende, su sentido.

En la crónica que se publica en nuevos medios la tradición literaria y la tecnología computacional están constantemente en diálogo. Para crear una historia interactiva en la red ya no participan solo periodistas: también lo hacen diseñadores, ilustradores, fotógrafos, camarógrafos, traductores y productores. Como los escritores de las diversas corrientes realistas desde el siglo pasado, los periodistas de medios digitales emplean métodos de investigación antropológica, especialmente técnicas etnográficas como la entrevista de campo, la observación participante y la historia oral o de vida; la diferencia aquí es que sus evidencias pueden convertirse en una historia alterna, que complementa la suya o incluso la modifica. Las crónicas en la red se convierten en complicados palimpsestos en los que las relaciones transtextuales (Genette 1991) o intertextuales (Kristeva, "Word..." 1980) entre los diversos discursos son cada vez más complejas. Esta serie de relaciones en diversos niveles que el género de la crónica contemporánea establece entre varios discursos (el textual y el audiovisual, pero también el periodístico, el literario y el etnográfico, por ejemplo) otorgarían, siguiendo a Genette, la "literaturiedad" a la obra cronística.

De esta manera, considero pertinente utilizar el concepto de "narrativa transmedia", discutido anteriormente, para referirse a las historias de no ficción que se difunden en la red empleando múltiples medios y no solo la palabra escrita. Estas narrativas entablan relaciones de diversos tipos con otros textos o medios, tanto al transmitir las historias de las víctimas como al elegir distintos formatos para hacerlo. Un ejemplo es

\footnotetext{
12 Este artículo no aspira a discutir en profundidad en torno a la literatura testimonial, aunque he abordado en otro lugar la relación entre crónica y el género testimonial como productos culturales latinoamericanos (Chávez Díaz 2017). Para una revisión panorámica de la crítica literaria en torno al testimonio latinoamericano ver la antología editada por Gugelberg (1996).
} 
De migrantes a refugiados: el nuevo drama centroamericano (2017) ${ }^{13}$. Este proyecto colectivo expone el fenómeno de la migración hacia Estados Unidos de América a través de video, audio, animación y textos, desde la perspectiva de varios migrantes, pero también de especialistas entrevistados y de los periodistas que narran sus historias. La crónica es aquí el género discursivo central, el que amalgama el resto de las historias contadas por otros medios. Sus autores son periodistas reconocidos en el género (Óscar Martínez, Carlos Martínez, Maye Primera), que cuentan su experiencia de investigación en primera persona empleando técnicas literarias (diálogos, discurso indirecto libre y descripciones). El espacio ofrecido a su relato es bastante amplio, pero está dividido, o interrumpido constantemente por videos que narran, en otra primera persona, las historias a las que también se refiere el cronista, así como fotografías que fueron tomadas durante sus viajes. Además, se ofrece la posibilidad de escuchar cada crónica en la voz de sus autores.

La obra está dividida en cuatro "libros" que fueron publicándose a manera de novela por entregas, entre el 8 y el 29 de octubre de 2017. Los libros pueden analizarse como obras independientes, aunque interconectadas por el mismo tema; cada uno tiene un autor de texto y un fotógrafo asignado. En esta sección analizaré solamente el primer libro, titulado "Los que iban a morir se acumulan en México" y dividido a su vez en 11 partes. Sobre todo me enfoco en las relaciones transtextuales o transmediáticas que la crónica del periodista salvadoreño Óscar Martínez mantiene con los otros medios que también conforman la obra. Propongo leer su crónica como eje articulador de la historia que, sin embargo, solo se completa al considerar también los otros discursos que conforman la obra transmedia total: las fotografías de Fred Ramos, las animaciones y los minidocumentales sin créditos específicos.

Aunque el texto inicia aparentemente en tercera persona, frases como "Ella recuerda..." o "Ella cuenta..." indican la presencia de un sujeto que escucha, indaga, que es testigo indirecto. Pronto se reconoce la voz en primera persona del narrador autorreferencial Óscar Martínez. Si bien este narrador no mantendrá una presencia tan activa en el texto como la

\footnotetext{
13 Este es un proyecto conjunto de Univisión (Estados Unidos de América) y El Faro (El Salvador) en el que participan al menos 40 personas, según los créditos publicados. Ha sido reconocido en diversos ámbitos: Premio Internacional de Periodismo Rey de España 2019 en la categoría de periodismo digital, Hillman Prize 2018 también en periodismo digital, premio a mejor historia multimedia de la National Press Photographers Association y finalista del Premio Gabo 2018 en categoría cobertura, otorgado por la Fundación Gabriel García Márquez para el Nuevo Periodismo Iberoamericano.
} 
de Caparrós, interviene lo suficiente como para advertir al lector que sus fuentes son de primera mano y reforzar así la credibilidad de su historia: "Son los últimos refugiados a los que veré en este viaje" (parte 1, párr. 12); "Han pasado siete días desde que esta investigación empezó. En solo una semana, he conversado con 29 personas que huyen. Familias con bebés, gays hondureños, expandilleros, niñas violadas, hombres mutilados." (párr. 13).

Antes del texto de Martínez, el lector puede ver un documental animado en el cual un hombre relata en primera persona su historia de refugiado. Las ilustraciones en movimiento acompañan el relato que surge de la memoria reciente. Este video ejemplifica el nivel más básico de relaciones transtextuales, el de la intertextualidad manifestada a través de la cita del discurso del otro. El texto de Óscar Martínez no es el único que conforma la obra; el lector está expuesto a videos breves que dialogan con otras primeras personas, como también es el caso del documental "Buscando la paz en México: Una familia dividida por la violencia de las maras", el cual es relatado en primera persona por la madre de una familia salvadoreña deportada de México. En ambos videos pareciera que la voz de las víctimas nos llega sin mediaciones, como si fuera una historia relatada por ellos mismos, con el acento y el vocabulario que le otorga una identidad distinta al autor del texto principal. Sin embargo, la historia tiene un límite de tiempo y es evidente que ha sido editada; el narrador interviene en frases escritas sobre la imagen en movimiento.

La ilusión polifónica es más difícil de sostenerse en el caso del "audiobook". Al inicio del texto, el lector es advertido que la lectura le tomará "unos 90 minutos" y se le invita a hacer click en el botón "escuchar relato". Narrada únicamente por Óscar Martínez, la historia en formato de audiolibro no hace diferencia entre la voz del narrador y la de los personajes citados de manera directa. La voz del autor se confunde con la de sus entrevistados, es una sola, sin inflexiones ni cambios de tono, libre de los signos lingüísticos que en la escritura marcan las diferencias entre distintos discursos.

La metatextualidad también está presente en la crónica de Martínez a manera de comentarios de tipo ensayístico, aunque de forma quizá más sutil, en tono menos irónico que en el caso de Caparrós:

Basta venir a este albergue, conversar con los que pasan el rato alrededor de la cancha, para darse cuenta de que una de las razones por las que el norte de Centroamérica no tiene una 
cifra de homicidios aún más espantosa es porque mucha de su gente se salva sola. Era gente muerta caminando. Decidieron, sin ayuda de ninguna autoridad, seguir viviendo. Se calcula que este año más de 20.000 personas pedirán asilo en México. Cuántos de ellos serían si no un número más en las estadísticas de la muerte centroamericana: ¿10, 100, 1.000, 10.000? (parte 8, párr. 7)

El periodista no opina más, pero una imagen en movimiento concluye la historia de manera que el lector-espectador tiene la última palabra. El video enfoca a varias personas que caminan de prisa por la orilla de una carretera selvática. La cámara se mueve lentamente desde un automóvil o eso aparenta; es un movimiento de cámara tipo travelling lateral que evoca una situación de vigilancia. El espectador toma la posición de quien observa a los migrantes desde una patrulla. Los migrantes observan directamente a la cámara, es decir, a los ojos del espectador, mientras caminan cada vez más de prisa; no hay sonido, pero sus bocas gesticulan y sus rostros muestran angustia. En la pantalla aparecen frases a manera de subtítulos que traducen las voces sin sonido propio: "atrás viene la migra”, “cuidado con la migra”, "escóndanse” (parte 8, párr. 7).

El narrador está ahí, escondido detrás de la cámara o de las frases en subtítulos; el narrador escucha, traduce, edita, aunque pocas veces se represente como un personaje más dentro de la historia. Sin embargo, Martínez elige el diálogo como recurso estilístico para narrar la última de las historias de su libro, la más corta:

Un salvadoreño solo está sentado en el comedor. Son casi las nueve de la noche. Los demás se preparan para dormir en el albergue. El recién llegado espera ser ubicado. Aún tiene la mochila en los hombros. Tiene la mirada perdida y asustada al mismo tiempo. Pierde la vista, pero reacciona con un espasmo a cada ruido a su alrededor.

—¿Qué ondas, hermano? ¿salvadoreño? — pregunto. Su cuerpo se estremece. Me voltea a ver.

-Sí. De Acajutla.

- ¿Huyendo?

-Huyendo.

—Huyendo - repito en voz alta. 
—Sí. Dicen que aquí uno puede vivir. (parte 12, párr. 1-7)

Sin duda, la acción de "huir" contra la de "migrar" o "viajar" es el hilo conductor de esta obra de Martínez. El viaje de los centroamericanos es distinto al del periodista que escucha su historia en los albergues mexicanos donde se han refugiado. Después de escuchar tantas historias, el narrador no ofrece una conclusión rotunda, pero muestra que ha aprendido su lenguaje, se ha confundido con ellos y es capaz de mantener una conversación que parece más la de dos compañeros de viaje que la de un periodista y su informante en situación de entrevista. Como en una novela posmoderna, el narrador de este tipo de crónicas ya no cuenta verdades o ya no está seguro de la verdad; no hay conclusiones después de varios meses de reportaje, se ha resignado a no entender su realidad y hasta dudar de ella: "Cuesta imaginar que mucha de esta gente, entregada al sopor, fue protagonista de huidas desesperadas hace no mucho" (parte 8, párr. 1); "Es difícil saber cuál fue el enfrentamiento al que se refiere. La conversación fue de paso. No le pregunté detalles." (párr. 3). El cronista, sin embargo, no renuncia a ser testigo y sigue relatando lo que escucha y ve.

\section{Conclusiones: el regreso del storyteller}

A principios del siglo XX, Walter Benjamin (1999) diferenciaba entre dos modos de comunicación entonces en pugna: la narración y la información. Para el teórico alemán, la narración — como la forma más antigua de comunicación humana- no aspira a transmitir la esencia pura de las cosas, como sí lo hace la información. Más bien, la narración sumerge las cosas en la vida del narrador (el storyteller, el contador de historias) ${ }^{14}$; el narrador, por lo tanto, toma lo que cuenta de su experiencia y la de otros. Benjamin compara el fenómeno con la imagen de una vasija de barro que al secarse queda marcada por las huellas de los dedos del alfarero (91). A la luz de estas reflexiones, cabe preguntarse si los cronistas latinoamericanos tienen más de narradores o de informadores. Propongo verlos como una mezcla de ambos: la crónica como respuesta contemporánea al problema de conservar la tradición y la memoria de sus pueblos, pero

14 En español la palabra "narrador" puede confundir, puesto que se refiere al sujeto de la enunciación en cualquier relato, oral o escrito. Sin embargo, Benjamin hace distinción entre el narrador proveniente de la cultura oral, más cercano al “cuentacuentos” latinoamericano, y el novelista. 
también como forma de transmitir información que no tiene lugar en los medios de comunicación convencionales.

De acuerdo con Benjamin, y a diferencia del novelista que para crear su obra debe aislarse, el narrador trabaja no solo con su voz, sino con su cuerpo: para poder transmitir sus historias, tiene que desplazarse, dislocarse, de manera que pueda escuchar y observar las vidas de los otros. El narrador regresa a su comunidad para re-contar lo que le han confiado, pero esas historias están ya filtradas por su propia experiencia. Este es el procedimiento que he buscado ejemplificar a través de los textos de Martín Caparrós y Óscar Martínez, pero que identifico como una tendencia de fin de siglo XX e inicios del XXI en los cronistas latinoamericanos, sobre todo aquellos que viajan para encontrar sus historias $^{15}$.

Más allá de la experimentación con el tiempo de la narración, a lo que en parte debe su nombre el género, la crónica contemporánea invita a reflexionar acerca del espacio. Esto se hace evidente sobre todo en las crónicas de migración, en las que tanto el informante como el periodista están en constante desplazamiento en contextos también movibles, violentos y ajenos. Este tipo de historias provocan pensar en espacios inestables en los que confluyen varios tiempos; espacios porosos por los que se desplazan cuerpos tan diversos que, sin embargo, coinciden e intercambian experiencias.

A pesar de las diferencias sociales que evidencian estas narrativas de manera consciente y comprometida, resulta interesante cómo sus autores intentan aminorar los rasgos de desigualdad en el encuentro con sus entrevistados, quienes se autodefinen como refugiados o migrantes y no como viajeros. Este encuentro con el otro, representado a través de los recursos estilísticos ya abordados aquí, permite al lector asomarse a posibilidades de acercamiento a una realidad más allá de lo que muestran los medios de comunicación tradicionales. El problema con las estrategias de autorrepresentación del narrador no está en el uso de la primera persona ni en la metaficción como dudoso recurso de verosimilitud, sino en la lectura de este tipo de narrativas como un recuento directo de las vidas de las víctimas de marginación o violencia.

\footnotetext{
15 Carrión (2009) hace una interesante observación respecto de la visión del viajero contemporáneo (metaviajero posmoderno, para él) y la idea del storyteller de Benjamin: en ambos, el narrador solo puede relatar la experiencia del viaje una vez que este ha terminado; es decir, no se relata ni el primer viaje, ni lo que en él se descubre de nuevo o exótico, sino el regreso y lo que queda en la memoria (26).
} 
Por lo tanto, considero más enriquecedor para los estudios literarios y mediáticos aproximarse a estas historias como un producto transtextual colectivo, o sea, un palimpsesto que integra las vidas de todos los involucrados en el proceso de la narración.

El discurso periodístico en América Latina ha sido el vínculo entre la producción literaria moderna y posmoderna (González 2006). Como producto de una modernidad tardía el periodismo implica un sistema de valores que no puede eliminarse de la ecuación tan fácilmente, puesto que al emplearse trae consigo consideraciones éticas de escritura. Al mismo tiempo, al volverse sobre sí mismo, al hacerse consciente de su papel dentro de la historia, el periodismo también cuestiona la relación entre el autor y el otro, entre la ficción y el mundo "real". Porque el periodismo, o al menos este tipo de periodismo que también es literatura, sigue cuestionando las (im)posibilidades de la representación de la verdad.

\section{Referencias bibliográficas}

Angulo Egea, María. "El realismo intransigente del periodismo literario de Martín Caparrós. Compromiso político, sentido histórico y voluntad de estilo". Estudios sobre el mensaje periodístico, vol. 22, no. 2, 2016, pp. 627-645.

Bakhtin, Mikhail. "Discourse in the novel”. The Dialogic Imagination. Four Essays. Ed. Michael Holquist. Trad. Caryl Emerson y Michael Holquist. Texas, University of Texas Press, 2011, pp. 259-422.

Benjamin, Walter. “The Storyteller”. Illuminations. Ed. Hannah Arendt. Trad. Harry Zorn. London, Pimlico, 1999, pp. 83-107.

Bush, Vannevar. “As We May Think”. The Atlantic. 1965. Recuperado de https://www.theatlantic.com/magazine/archive/1945/07/ as-we-may-think/303881/

Caparrós, Martín. Una luna. Diario de hiperviaje. Barcelona, Anagrama, 2009.

Carrión, Jorge. "Retrato robot del viajero posmoderno". Viaje contra espacio. Juan Goytisolo y W. G. Sebald. Madrid, IberoamericanaVervuert, 2009, pp. 13-29.

Carrión, Jorge. Editor. Mejor que ficción. Crónicas ejemplares. Barcelona, Anagrama, 2012. 
Chávez Díaz, Liliana. Based on True Stories: Representing the Self and the Other in Latin American Documentary Narratives. PhD. Dissertation University of Cambridge, 2017. https://doi. org/10.17863/CAM.13741

Chillón, Albert. La palabra facticia. Literatura, periodismo y comunicación. Barcelona, Universitat Autònoma de Barcelona, Universitat Juame I, Universitat Pompeu Fabra, Universitat de València, 2014.

Diaconu, Diana. "La autoficción: simulacro de teorías o desfiguraciones de un género". La Palabra, no. 30, enero-junio, 2017, pp. 35-52.

Genette, Gérard. Palimpsests: Literature in the Second Degree. Trad. Channa Newman y Claude Doubinsky. Nebraska, University of Nebraska Press, 1991.

González, Aníbal. Journalism and the Development of Spanish American Narrative. Cambridge, Cambridge University Press, 2006.

Gosciola, Vicente. "Narrativa transmídia: conceituação e origens". Narrativas transmedia, entre teorías y prácticas. Eds. Carolina Campalans, Denis Renó y Vicente Gosciola. Bogotá, Universidad del Rosario, 2012, pp. 7-14.

Grishakova, Marina y Marie-Laure Ryan. “Editors' Preface”. Intermediality and Storytelling. Göttingen, De Gruyter, 2010, pp. 1-7.

Gugelberg, Georg. Editor. The Real Thing: Testimonial Discourse and Latin America. Durham y London, Duke University Press, 1996.

Hutcheon, Linda. A poetics of Postmodernism: History, Theory, Fiction. London, Routledge, 1988.

. Narcissistic Narrative: The Metafictional Paradox. New York, Methuen, 1984.

Jaramillo, Darío. Editor. Antología de crónica latinoamericana actual. Madrid, Alfaguara, 2012.

Jenkins, Henry. “Transmedia Storytelling 101". Confessions of an Aca-Fan, The Official Weblog of Henry Jenkins. 2007, párr. 2. Recuperado de http://henryjenkins.org/blog/2007/03/transmedia_ storytelling 101.html

Kraniauskas, John. "Introduction. Critical Closeness: The Chronicle-Essays of Carlos Monsiváis". Carlos Monsiváis, Mexican Postcards. Ed. y Trad. John Kraniauskas. Londres, Verso, 1997, pp. ix-xxii. 
Kristeva, Julia. “The Bounded Text”. Desire in Language. A Semiotic Approach to Literature and Art. Ed. Leon S. Roudiez. Trad. Thomas Gora, Alice Jardine y Leon S. Roudiez. New York, Columbia University Press, 1980, pp. 36-63.

"Word, Dialogue, and the Novel". Desire in Language. A Semiotic Approach to Literature and Art. Ed. Leon S. Roudiez. Trad. Thomas Gora, Alice Jardine y Leon S. Roudiez. New York, Columbia University Press, 1980, pp. 64-91.

Lejeune, Philippe. Le désir biographique. Paris, Université de Paris X, 1989.

Mahieux, Viviane. "Cities, Publics, and Urban Chroniclers in Latin America: 1920s-1930s". Urban Chroniclers in Modern Latin America. The Shared Intimacy of Everyday Life. Texas, University of Texas Press, 2011, pp. 12-31.

Martínez, Óscar. "Los que iban a morir se acumulan en México". De migrantes a refugiados: el nuevo drama centroamericano. Univisión/El Faro, 2017. Recuperado de https://www.univision. com/especial/noticias/america-latina/de-migrantes-arefugiados-el-nuevo-drama-centroamericano/

"Natalia Moldova, víctima del tráfico de personas". Jóvenes en movimiento. Población Mundial 2006 Suplemento Jóvenes. Coord. por Laura Laski y Saskia Schellekens. New York, United Nations Population Fund., 2007, pp. 25-29.

Nelson, Ted. "A File Structure for the Complex, the Changing, and the Indeterminate", ACM 20 ${ }^{\text {th }}$ National Conference/1965. Internet Archive, 2017. Recuperado de https://archive.org/details/ nelson-file-structure/page/n1

Premio y Festival Gabriel García Márquez de Periodismo. “De migrantes a refugiados". Premioggm, 2018. Recuperado de https:// premioggm.org/2018/finalistas/cobertura/de-migrantes-arefugiados-el-nuevo-drama-centroamericano/

Primera, Maye et. al. De migrantes a refugiados: el nuevo drama centroamericano. Univisión/ El Faro. 2019. Recuperado de, https://www.univision.com/especial/noticias/americalatina/de-migrantes-a-refugiados-el-nuevo-dramacentroamericano/

Renó, Denis. “Transmedia Journalism and the New Media Ecology: Possible Languages". Periodismo transmedia: miradas 
múltiples. Denis Renó et al. Ed. Bogotá, Universidad del Rosario, 2013, pp. 3-19.

Rodríguez-Luis, Julio. El enfoque documental en la narrativa hispanoamericana. Estudio taxonómico. Ciudad de México, Fondo de Cultura Económica, 1997.

Rotker, Susana. La invención de la crónica. Ciudad de México, Fondo de Cultura Económica, 2005.

Skirius, John. Editor. El ensayo hispanoamericano del siglo XX. Ciudad de México, Fondo de Cultura Económica, 2004.

Univisión Noticias y El Faro. De migrantes a refugiados: el nuevo drama centroamericano. 2017. Recuperado de https://www.univision. com/especial/noticias/america-latina/de-migrantes-arefugiados-el-nuevo-drama-centroamericano/

Weinberg, Liliana. El ensayo en busca del sentido. Madrid, Iberoamericana Vervuert, 2014. 